RU Немецкоязычные военные терминологические заимствования в английский язык в первой половине XX века (период мировых войн)

\author{
Варушкина А. В., Переходченко К. С., Панкова Т. Н.
}

\begin{abstract}
Аннотация. Цель исследования - определить влияние заимствованных немецкоязычных военных терминов на развитие военной терминосферы английского языка в первой половине XX века. Научная новизна состоит в том, что впервые проводятся анализ особенностей тематики заимствованных немецкоязычных военных терминов и изучение характерных моделей интеграции германизмов в английский военный лексикон. Полученные результаты свидетельствуют о том, что германизмы оказали значительное влияние на развитие терминосферы английского языка периода мировых войн, обогатив ее актуальными понятиями военно-политической, общевоенной, военно-технической областей. Подчеркивается, что адаптацию германизмов характеризует разнообразие моделей, реализуемых на графическом, морфологическом и семантическом уровнях.
\end{abstract}

\title{
Borrowings of the German Military Terminology in the English Language in the First Half of the XX Century (Period of the World Wars)
}

\author{
Varushkina A. V., Perehodchenko K. S., Pankova T. N.
}

\begin{abstract}
The paper aims to reveal the role of the German borrowings in the process of the English military terminology formation in the first half of the XX century. Scientific originality of the study lies in the fact that the researchers for the first time suggest a thematic classification of the borrowed military terms, identify the most frequent models of the Germanisms assimilation in military English. The conducted research allows concluding that the German borrowings of that period influenced considerably the formation of the English military terminology, replenishing it with the relevant terms of the military-political, allmilitary, military-technical sphere. It is shown that the Germanisms assimilation occurred at graphical, morphological and semantic levels.
\end{abstract}

\section{Введение}

Актуальность исследования обусловлена интенсивностью процесса иноязычных заимствований в английский язык, в том числе в области военной деятельности. Научно-техническая терминосфера, как правило, пополняется терминами, перенесенными из других языков [1, с. 7]. Заимствованная военная лексика, преимущественно из французского, латинского, итальянского, немецкого и других языков, прочно вписалась в военную терминологию современного английского языка [2, с. 108; 9].

Следует отметить, что большинство отечественных и зарубежных исследований посвящено изучению места и роли французских заимствований в английском лексиконе, в том числе в военном [2; 11], либо влиянию британского/американского языка на немецкий [5]. Традиционно считается, что немецкие терминологические заимствования играют незначительную роль в современном английском языке.

Вместе с тем отдельные исследования посвящены истории вхождения немецких заимствований в английский язык [5; 14]; изучению моделей адаптации германизмов [6], выявлению тематического спектра немецкоязычных заимствований [5]; рассмотрению роли заимствованных германизмов в формировании культурных стереотипов [17]. Отсутствуют специальные работы, нацеленные на анализ заимствованных немецкоязычных военных терминов в английском языке в первой половине XX века (период мировых войн (1914-1945)).

Задачи исследования:

1) охарактеризовать влияние военных конфликтов на развитие терминосферы; 
2) определить тематические поля немецкоязычных заимствований в английский военный лексикон указанного периода;

3) выявить модели вхождения немецких военных терминов в английский язык.

Материалом исследования послужили немецкоязычные заимствования периода мировых войн в английском языке военной сферы, отобранные в толковых, отраслевых и этимологических словарях [3; 10; 12$]$.

В качестве методов исследования использовались методы анализа и синтеза, лингвистическое описание с привлечением этимологического, семантического, морфологического, компонентного анализа, сопоставление, классификация, обобщение полученных данных.

Теоретической базой исследования стали работы таких российских языковедов, как В.В. Виноградов, В. М. Лейчик, С. В. Гринев, Д. С. Лотте, В. Д. Аракин и др., а также зарубежных авторов, в числе которых Ф. Дуркин, Дж. Кэннон, Дж. Пфеффер, К. Бэст, Дж. Кеблер и др.

Практическая значимость работы заключается в возможности использования ее результатов в развитии дальнейших исследований по сопоставительной лингвистике, возможности использовать материалы в процессе учебно-методической деятельности при создании учебников, учебных пособий и практикумов по дисциплине «История английского языка», а также спецсеминаров военно-научной школы курсантов.

\section{Влияние военных конфликтов на процесс вхождения иноязычных лексем}

Иноязычные заимствования представляют собой один из способов номинации новых понятий и явлений посредством переноса в терминологию данного языка терминов, существующих в другом языке [1, с. 7]. Зачастую такой перенос и последующая адаптация лингвистического материала из другого языка являются результатом языковых контактов [7, p. 132]. Продуктивное языковое взаимодействие наблюдается в период значимых, переломных исторических процессов и событий.

Как справедливо отмечает А. Патерсон (A. Paterson), война сильно воздействует на язык [13, p. 145]. В период военных столкновений, особенно в мировом масштабе, появляются новые военные технологии, техника, стратегии ведения боевых действий, что имеет огромное влияние на развитие языка. Контакты в военнополитической сфере, боевые действия в значительной степени создают благоприятные условия для интенсификации проникновения иноязычных заимствований в речевую среду английского языка.

\section{Тематический спектр немецкоязычных заимствований в английский язык военной сферы}

История немецких заимствований в английском языке начинает отсчет с середины XIV столетия (первое немецкое заимствование “snorkle” датируется в английской литературе 1346 годом) и насчитывает порядка 6000 терминов.

Наиболее заметное и глубокое влияние германизмы оказали на формирование естественнонаучной терминосферы английского языка с середины XIX по начало XX в. (в этот период было заимствовано порядка 1280 лексем) [14].

Как свидетельствуют работы зарубежных авторов, большинство немецкоязычных заимствованных терминов в английском языке относятся к области естественных наук: горному делу, химии, биологии, геологии, математике, медицине и т.д. [5; 7; 14]. Таким образом, германизмы оставили значительный след в сфере профессионального английского языка, обогатив его терминами из областей науки и культуры, а также в повседневном лексиконе [17].

Думается, несмотря на то, что немецкий язык был языком противника Великобритании и Америки в мировых войнах, его статус как языка науки, в том числе военно-технической, был достаточно высок в рассматриваемый период [7, p. 143].

Так, заимствованные в первой половине XX века немецкие военные термины можно разделить на следующие тематические группы:

- заимствования военно-политического характера:

schrecklichkeit (1915) - нем. Schrecklichkeit (policy of horror and terrorism at war - политика запугивания и террора в военное время) (здесь и далее перевод выполнен авторами статьи. - A. В., К. П., Т. П.);

Reich (1945) - нем. Reich (Рейх, немецкое государство);

gestapo (1934) - нем. geheime Staats-polizei, Gestapo (гестапо, гестаповский);

national socialist - нем. Nazionalsozialist (национал-социалист);

holocaust (1944) - нем. Holocaust (преследование и массовое уничтожение евреев, живших в Германии, на территории ее союзников и на оккупированных ими территориях, во время Второй мировой войны (1933-1945 г2.)) [6; 10; 12];

- общевоенные термины и реалии:

Wehrmacht (1935) - нем. Wehrmacht (Вермахт, ВС Германии);

stalag (1940) - нем. Stammlager, Stalag (шталаг, лагерь для военнопленных (рядовых и унтер-офицеров));

landwehr - нем. Landwehr (категория военнообязанных запаса 2-й очереди и создававшиеся из них в военное время второочередные воинские формирования);

landsturm - нем. Landsturm (категория военнообязанных запаса 3-й очереди и создававшиеся из них в военное время вспомогательные воинские формирования. В фашистской Германии в 1944 г. был заменен фолькштурмом) [3; 4; 9]; 


\section{- тактические термины:}

blitzkrieg (1939) - нем. Blitzkrieg (блицкриг, молниеносная война);

air raid (1914) - нем. Fliegerangriff (атака с воздуха, авианалет);

anti-aircraft defense (1915) - Flieger Abwehr (противовоздушная оборона) [12];

- термины, обозначающие наименования вооружения:

U-boat (1916) - нем. Unterseeboot (подводная лодка);

Jager (WWI) - нем. Jäger (самолет-истребитель);

aircraft defense cannon / gun (1938-1940) - нем. Fliegerabwehrkanone (сокр. Flak) (зенитная артиллерия) [Ibidem].

Думается, влияние германизмов на развитие военного лексикона английского языка указанного периода достаточно значительно и разнообразно: это и терминологические заимствования, относящиеся преимущественно к наименованию вооружения и техники, произведенных Германией в Первой Мировой войне; стратегиям ведения боевых действий, опробованным Германией в указанный период; военно-политические термины и реалии.

\section{Модели интеграции немецких военных терминов}

Как правило, когда речь идет о немецкоязычных заимствованиях в английском языке, ученые сходятся во мнении, что они заимствуются в «готовом виде» с незначительной фонетической, орфографической адаптацией к принимающему языку [6; 8; 16]. Согласно, Ф. Дуркину (Ph. Durkin), германизмами (Germanism) являются лексемы, которые показывают отчетливый след исходного заимствованного слова в определенном языке [7, p. 140].

Наше исследование показало, что интеграция немецких терминов представлена более разнообразными моделями.

Согласимся с мнением Дж. Харбека (J. Harbeck) в том, что буквальное заимствование, заключающееся в переносе иноязычного термина «в чистом виде», является достаточно продуктивным вариантом терминообразования в военной, политической сферах [8]. Например:

panzer - нем. Panzer (броня, танк; бронетанковые войска);

blitzkrieg, blitz (1939) - нем. Blitzkrieg (sudden overwhelming attack - блицкриг, молниеносная война) [10; 12].

Отметим, что военные термины немецкого происхождения представляют собой в английском языке модели построения многокомпонентных терминов:

minenwerfer - нем. Minenwerfer (short-range mortars used extensively by the German Imperial Army; Minen (мины)+Werfer (метатель) - минометы малой дальности, применяемые немецкими войсками);

panzerdivision (1940) - нем. Panzerdivision (armoured unit; Panzer (броня) + Division (дивизия) - бронетанковая дивизия) [12].

Предположим, что таким образом заимствуются сложные понятия, подходы к ведению военных действий. Приведем примеры:

Drang nach Osten (1906) - нем. Drang nach Osten (политика территориальной экспансии);

realpolitik (1914) - нем. Realpolitik (practical politics - реальная политика);

machtpolitik - нем. Machtpolitik (a doctrine on political theory advocating the use of power especially of physical force политика силы);

Vorsprung durch Technik - преимущество благодаря технике [3; 10; 12].

Иным вариантом вхождения германизмов в терминосистему языка-реципиента являются трансформируемые заимствования, в которых происходят некоторые изменения на морфологическом уровне (корень, аффикс, окончание):

strafe (1915) - нем. strafen (shoot up ground positions from low-flying aircraft - обстреливать наземные позиции с самолета на бреющем полете - атаковать, наносить удар, обстреливать с бреющего полета);

storm troopers (1917) - нем. Sturmtrupреп (цтурмовые части, ударные войска) [10; 13; 15].

Переводные заимствования («кальки») с немецкого языка нередко становятся моделью образования сложносоставных терминов в английском языке:

anti-aircraft defense (1915) - нем. Flieger Abwehr (противовоздушная оборона);

aircraft defense cannon (WWI) - нем. Fliegerabwehrkanonе (зенитная пушка);

death caтр (1940) - нем. Todeslager, Vernichtungslager (концентрационный лагерь) [12; 15].

Выскажем предположение, что способность германизмов распадаться на отдельные лексемы (в отличие от терминов греческого, латинского, французского происхождения) и образовывать из этих элементов многокомпонентные термины стала причиной активного проникновения научной терминологии немецкого происхождения в английский язык.

Моделью образования новых терминов служат лексемы с включением иноязычных элементов (терминыгибриды):

Zeppelin ship (1900) - нем. Zeppelinschiff (цеппелин, дирижабль);

U-boat (1916 registered, 1913 in иse) - нем. Unterseeboot (подводная лодка) [12].

Отметим, что метонимия (перенос наименования на основе смежности имени изобретателя, владельца изобретения и изобретения) является продуктивной моделью развития семантики заимствованных германизмов. Например:

schmeisser - нем. Schmeisser (название немецкого автоматического оружия StG 44 по имени его конструктора Хуго Шмайссера (1884-1953), автомат, шмайсер, автомат шмайсер); 
Zeppelin (1900) - нем. Zeppelinschiff (название немецкого дирижабля по имени его изобретателя Фердинанда фон Цеппелина (1838-1917), цеппелин, дирижабль);

Big Bertha (WWI) - нем. Bertha (название немецкой мортиры по имени владелицы завода Берты Крупп (1886-1957), тяжелая мортира «Большая Берта») [10; 12].

\section{Заключение}

Выводы. Германизмы оказали достаточно значительное влияние на развитие военной терминосферы английского языка в первой половине XX века. Некоторые военные термины немецкого происхождения, заимствованные в период мировых войн, прочно вошли в военный лексикон английского языка и активно используются по сей день.

В исследовании было охарактеризовано влияние военных конфликтов на развитие терминосферы. Участие разных стран в военных столкновениях, будь то в качестве противников или союзников, создает предпосылки для языковых контактов не только на уровне повседневного общения, специальной военной коммуникации, но и на уровне терминотворчества.

В работе были четко определены тематические поля немецкоязычных заимствований в английский военный лексикон в первой половине XX века. В период мировых войн в состав английского языка вошел ряд заимствований немецкого происхождения, которые обогатили словарный состав английского языка актуальными понятиями и явлениями военно-политической, общевоенной, авиационно-технической сфер.

В исследовании выявлены модели интеграции немецких военных терминов в английский язык. Адаптацию германизмов, заимствованных в военную терминосферу английского языка в первой половине XX века, характеризует разнообразие моделей (буквализм, трансформируемое заимствование, «калька», гибридное заимствование, семантическая трансформация), реализуемых на графическом, морфологическом и семантическом уровнях.

Думается, что перспективы дальнейшего исследования заключаются в рассмотрении изменений семантического значения немецкоязычных военных терминов в диахроническом аспекте, что позволит оценить степень усвоенности принимающим языком заимствованной лексики, выявить направления развития значений германизмов в английском языке.

\section{Список источников}

1. Лотте Д. С. Вопросы заимствования и упорядочения иноязычных терминов и терминоэлементов. М.: Наука, 1982. 147 c.

2. Мунгалова Т. И., Федотова И. П. Заимствованная военная лексика в английском языке в диахроническом аспекте // Вестник Северного (Арктического) федерального университета. Серия «Гуманитарные и социальные науки». 2018. № 3. С. 106-115.

3. Словарь иностранных слов / под ред. Ф. Н. Петрова. Изд-е 18-е. М.: Рус. яз., 1989. 624 с.

4. Сокращения в немецких документах [Электронный ресурc]. URL: http://www.maparchive.ru/index.php/ 2011-12-16-14-10-41.htm (дата обращения: 22.11.2020).

5. Best K.-H. Deutsche Entlehnungen im Englischen [Электронный ресурс] // Glottametrics 13. 2006. S. 66-72. URL: www.ram-verlag.eu/wp-content/uploads/2018/08/g13zeit.pdf (дата обращения: 20.11.2020).

6. Cannon J. Post-1949 German loans in written English [Электронный ресурс] // Word. 1998. Vol. 49. Iss. 1. URL: https://www.tandfonline.com/doi/abs/10.1080/00437956.1998.11673877 (дата обращения: 20.09.2020).

7. Durkin Ph. The Oxford guide to etymology. Oxford: Oxford University Press, 2009. $350 \mathrm{p}$.

8. Harbeck J. Linguistic invasion! The foreign influence of English's political and military words (2013) [Электронный ресурс]. URL: http://theweek.com/articles/462437/linguistic-invasion-foreign-influence-englishspolitical-military-words (дата обращения: 26.11.2020).

9. Köbler G. Deutsches Etymologisches Wörterbuch (1995) [Электронный ресурс]. URL: http://koeblergerhard.de (дата обращения: 17.11.2020).

10. Merriam-Webster Dictionary [Электронный ресурc]. URL: http://www.merriamwebster.com (дата обращения: 02.12.2020).

11. Mitchell P. J., Akhtambaev R. P., Ignatov A. A. The influence of military contacts on French loanwords in the English language [Электронный ресурс] // Language and Culture. 2014. № 2. URL: http://journals.tsu.ru/engine/download. php?id=68444\&area=files (дата обращения: 20.09.2020).

12. Online Etymology Dictionary [Электронный ресурc]. URL: http://etymonline.com (дата обращения: 13.12.2020).

13. Paterson A. New Words, New World Order: The Vocabulary of a Modern Warfare // Procedia. Social and Behavioral Sciences. 2014. № 154. P. 144-147.

14. Pfeffer J. A., Cannon G. German Loanwords in English: A Historical Dictionary. Cambridge: Cambridge University Press, 1994. $416 \mathrm{p}$.

15. Pulford A. Release notes: The language of World War I [Электронный ресурс] // Oxford English Dictionary. URL: https://public.oed.com/blog/june-2014-update-release-notes-the-language-of-world-war-i/ (дата обращения: 26.11.2020). 
16. Smith E. High German loanwords in English Germanic studies [Электронный pecypc]. URL: http://germanic.eu/ High-German-loanwords-in-English.htm (дата обращения: 29.11.2020).

17. Stubbs M. German loanwords and cultural stereotypes // English Today. 1998. Vol. 14. Iss. 1. P. 19-26.

\section{Информация об авторах | Author information}

RU Варушкина Анастасия Валерьевна ${ }^{1}$, к. филол. н., доц. Переходченко Каролина Сергеевна ${ }^{2}$ Панкова Татьяна Николаевна ${ }^{3}$, к. филол. н.

1,2 Военно-учебный научный центр Военно-воздушных сил «Военно-воздушная академия имени проф. Н. Е. Жуковского и Ю. А. Гагарина», г. Воронеж

${ }^{3}$ Воронежский государственный университет

EN Varushkina Anastasia Valerievna ${ }^{1}, \mathrm{PhD}$

Perehodchenko Karolina Sergeevna ${ }^{2}$ Pankova Tatiana Nikolaevna ${ }^{3}$, PhD

${ }_{1,2}$ Military Educational and Scientific Centre of the Air Forces "Air Force Academy named after prof. N. E. Zhukovskiy and Yu. A. Gagarin”, Voronezh

${ }^{3}$ Voronezh State University

${ }^{1}$ nastzher@yandex.ru, ${ }^{2}$ dmitry48@yandex.ru, ${ }^{3}$ pankova@rgph.vsu.ru

\section{Информация о статье | About this article}

Дата поступления рукописи (received): 12.12.2020; опубликовано (published): 10.02.2021.

Ключевые слова (keywords): заимствование; германизм; военная терминосфера; английский язык; borrowing; Germanism; military terminological sphere; English language. 